\title{
Ventilatory Response to Carbon Dioxide during Moderate Exercise
}

\author{
Masayoshi TaKahashi' ${ }^{1}$, Yoshihiro Mano $^{2}$, Masaharu Shibayama $^{3}$ and Nobuo Yamami ${ }^{2}$ \\ 'National Institute for Resources and Environment, \\ ${ }^{2}$ Tokyo Medical and Dental University, \\ ${ }^{3}$ Komazawa Women's University
}

\begin{abstract}
Ventilatory Response to Carbon Dioxide during Moderate Exercise: Masayoshi TAKAHASH, et al. National Institute for Resources and Environment-Elevated carbon dioxide $\left(\mathrm{CO}_{2}\right)$ concentration is one of the most important physiological stressors with closed-circuit breathing-apparatus (CCBA). We determined the ventilatory response to $\mathrm{CO}_{2}$ during moderate exercise by measuring the relationship between $\dot{V}_{E}$ and $P_{E T} C_{2}$. Based on our findings, it is recommended that the permissible inhaled $\mathrm{CO}_{2}$ limit for CCBA in the Japan Industrial Standard (JIS) be lowered from $3 \%$ to $2 \%$, and that the members of a rescue or fire fighter team who use CCBA be selected on the basis of their ventilatory sensitivity to $\mathrm{CO}$.

(J Occup Health 2000; 42: 79-83)
\end{abstract}

Key words: Carbon dioxide, Ventilatory response, Steady-state method, Moderate exercise, Closedcircuit breathing-apparatus, Japan Industrial Standard

Closed-circuit breathing-apparatuses (CCBAs) are important tools for rescue and escape activities in an irrespirable atmosphere. But the apparatus inherently impose several physiological stressors, with elevated inhaled carbon dioxide $\left(\mathrm{CO}_{2}\right)$ concentrations being one of the most important. The increase in ventilation rate due to the $\mathrm{CO}_{2}$ stimulus is the most significant concern for CCBA designers and government certifying agencies, since this results in higher breathing pressure, which is another CCBA stressor. Read's rebreathing technique ${ }^{1}$ is the most common method for evaluating a person's ventilatory response to $\mathrm{CO}_{2}$ at rest. Some research studies use this method during exercise ${ }^{2-6)}$. But there are several problems inherent in the use of this technique during exercise, such that the effect of exercise on the response may not be correctly evaluated. In order to ensure the

Received Aug 4, 1999; Accepted Dec 4, 1999

Correspondence to: $M$. Takahashi, National Institute for Resources and Environment, 16-3 Onogawa, Tsukuba, Ibaraki 305-8569, Japan safe performance of CCBA at moderate to high work rates, the ventilatory response to $\mathrm{CO}_{2}$ during exercise is important in deciding the appropriate permissible level of inhaled $\mathrm{CO}_{2}$. The purpose of the study is to determine the effect of exercise on the ventilatory response, and to evaluate the appropriateness of the permissible level of the inhaled $\mathrm{CO}_{2}$ concentration for CCBA.

\section{Methods}

Steady-state $\mathrm{CO}_{2}$ inhalation was employed to measure the ventilatory response. Figure 1 shows a schematic diagram of the system, which continuously measured the subject's ventilation rate and end-tidal $\mathrm{CO}_{2}$ concentration breath-by-breath. A subject wore a half-mask, inhaling gas from the conditioning chamber through the inhalation tube. The dead space of the mask was about $150 \mathrm{~m} l$. A blower delivered ambient air to the chamber where $\mathrm{CO}_{2}$ was mixed if needed for a particular condition. Exhaled gas passed through the exhalation tube to the ambient air. Gas analyzers measured the amount of oxygen and $\mathrm{CO}_{2}$ in the gases in the conditioning chamber and the exhalation tube. The analyzers were calibrated with precision-analyzed gas mixtures before and after each test. A pneumotachometer measured the volume of the gas flow in the inhalation tube. The coefficient of viscosity of the inhaled air, which was needed to determine the volume precisely, was calculated from the composition of the gas and its temperature and humidity. A pressure gage measured the pressure level inside the mask. After converting from analog to digital, the signals from these devices were processed with a personal computer for the determination of ventilation $\left(\mathrm{V}_{\mathrm{E}}\right)$ and end-tidal $\mathrm{CO}_{2}$ concentration $\left(\mathrm{P}_{\mathrm{ET}} \mathrm{CO}_{2}\right)$.

Twelve male subjects (Table 1), ranging in age from 28 to $46 \mathrm{yr}$, volunteered to participate in the tests with knowledge of the possible risks. None were aware of the purpose of the experiment. Their average height was about $170 \mathrm{~cm}$ and their average weight was about $68 \mathrm{~kg}$. The four test conditions were breathing room air or $3 \%$ $\mathrm{CO}_{2}$ at rest or during exercise. The $3 \% \mathrm{CO}_{2}$ level was 


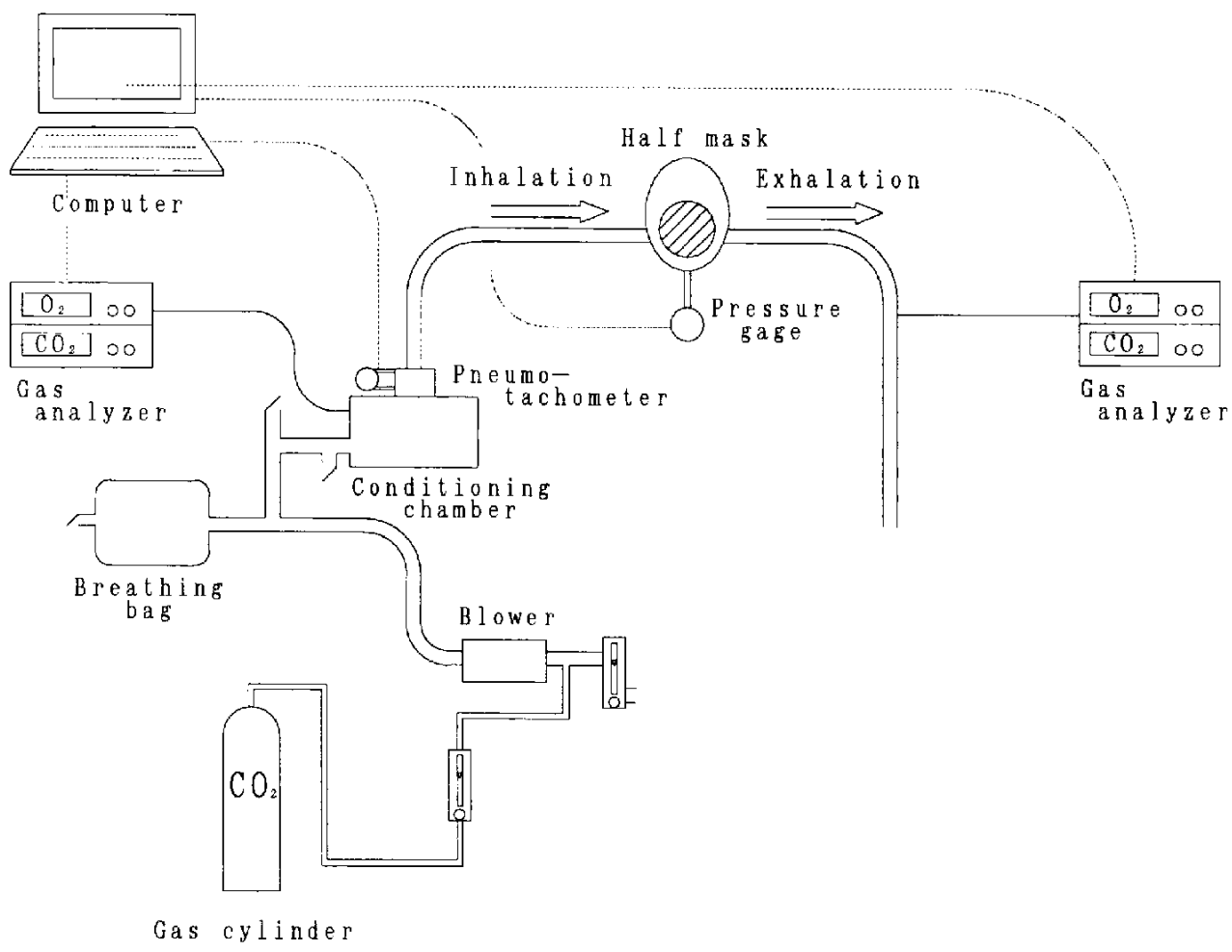

Fig. 1. Schematic diagram of the measuring system

Table 1. Physical characteristics of subjects

\begin{tabular}{cccc}
\hline Subject & $\begin{array}{c}\text { Age } \\
(\text { years })\end{array}$ & $\begin{array}{c}\text { Height } \\
(\mathrm{cm})\end{array}$ & $\begin{array}{c}\text { Weight } \\
(\mathrm{kg})\end{array}$ \\
\hline A & 38 & 175 & 70 \\
B & 46 & 180 & 86 \\
C & 28 & 167 & 64 \\
D & 30 & 168 & 68 \\
E & 30 & 163 & 60 \\
F & 35 & 180 & 68 \\
G & 44 & 170 & 75 \\
H & 39 & 160 & 63 \\
I & 37 & 172 & 75 \\
J & 30 & 170 & 65 \\
K & 30 & 164 & 60 \\
L & 28 & 167 & 61 \\
\hline Mean & 34.6 & 169.7 & 67.9 \\
\pm SD & 6.2 & 6.3 & 7.7 \\
\hline
\end{tabular}

chosen on the basis of its being the permissible limit in the Japan Industrial Standard (JIS) ${ }^{7}$ for CCBA. The order in which room air or $3 \% \mathrm{CO}_{2}$ was administered was randomized. And throughout the test the heart rate of the subject was measured by an electrocardiograph.

A subject sat on a bicycle ergometer while breathing the test gases at room temperature $\left(23 \pm 1^{\circ} \mathrm{C}\right)$. After initial familiarization with the test conditions, data acquisition was started. The subject breathed through the mask at rest for $2 \mathrm{~min}$, and started exercising by rotating the pedals at $60 \mathrm{rpm}$ with a $20-\mathrm{W}$ work load. After 1 min of cycling at this initial exercise load, the power output was increased every minute by $20 \mathrm{~W}$ until it reached approximately $40 \%$ of the maximum working capacity of the subject. The intensity of the work load of the subject while exercising was determined by the heart rate whose maximum value was evaluated from the age of the subject. This work rate was chosen as the highest intensity possible without a significant effect of lactic acid production. The subject continued the test for at least $3 \mathrm{~min}$ at the highest work load.

\section{Results}

Figures 2 and 3 show the ventilation rates and the endtidal $\mathrm{CO}_{2}$ concentrations, respectively, of one test subject. During the first $2 \mathrm{~min}$ at the rest condition, the values were almost stable. After starting exercise, the ventilation rate increased with the increasing intensity of the work load, and reached a stable level while steady-state exercising for the last $3 \mathrm{~min}$. The ventilation rate while the subject was breathing $3 \% \mathrm{CO}_{2}$ was higher than that while breathing room air throughout the test; this was also true for end-tidal $\mathrm{CO}_{2}$. 


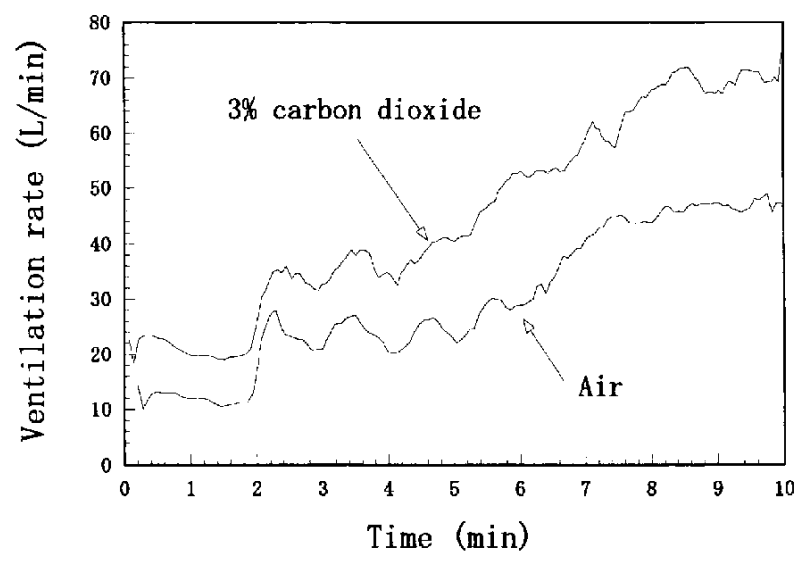

Fig. 2. Ventilation rate of a subject while breathing air or $3 \%$ carbon dioxide

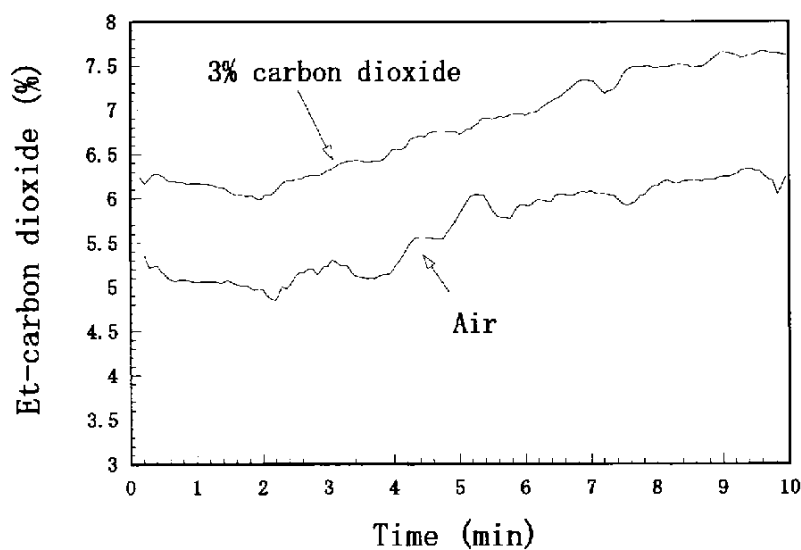

Fig. 3. End-tidal carbon dioxide concentration of the subject while breathing air or $3 \%$ carbon dioxide

Table 2. Ventilation rate, end-tidal carbon dioxide concentration and slope of $\dot{\mathrm{V}}_{\mathrm{E}}-\mathrm{P}_{\mathrm{FT}} \mathrm{CO}_{2}$ relationship

\begin{tabular}{|c|c|c|c|c|c|c|c|c|c|c|c|}
\hline \multirow{3}{*}{ Subject } & \multirow{3}{*}{$\begin{array}{c}\text { Exercise } \\
\text { intensity } \\
\text { (W) }\end{array}$} & \multicolumn{4}{|c|}{$\dot{\mathrm{V}}_{\mathrm{E}}(\mathrm{L} / \mathrm{min})$} & \multicolumn{4}{|c|}{$\mathrm{P}_{\mathrm{ET}} \mathrm{CO}_{2}(\%)$} & \multicolumn{2}{|c|}{ Slope $(\mathrm{L} / \mathrm{min} / \%)$} \\
\hline & & \multicolumn{2}{|c|}{ Rest } & \multicolumn{2}{|c|}{ Exercise } & \multicolumn{2}{|c|}{ Rest } & \multicolumn{2}{|c|}{ Exercise } & \multirow[t]{2}{*}{ Rest } & \multirow[t]{2}{*}{ Exersise } \\
\hline & & Air & $\mathrm{CO}_{2}$ & Air & $\mathrm{CO}_{2}$ & Air & $\mathrm{CO}_{2}$ & Air & $\mathrm{CO}_{2}$ & & \\
\hline A & 120 & 12 & 20 & 65 & 90 & 5.2 & 5.6 & 6.2 & 7.0 & 20.0 & 31.3 \\
\hline $\mathrm{B}$ & 120 & 12 & 21 & 47 & 68 & 5.1 & 6.1 & 6.2 & 7.6 & 9.0 & 13.6 \\
\hline $\mathrm{C}$ & 100 & 8 & 16 & 30 & 42 & 4.8 & 6.0 & 6.2 & 7.6 & 6.7 & 8.6 \\
\hline $\mathrm{D}$ & 100 & 8 & 12 & 40 & 46 & 5.0 & 6.1 & 7.4 & 8.5 & 3.6 & 5.4 \\
\hline $\mathrm{E}$ & 100 & 11 & 18 & 35 & 42 & 4.7 & 6.3 & 6.4 & 8.1 & 4.4 & 4.1 \\
\hline $\mathbf{F}$ & 120 & 10 & 13 & 46 & 50 & 5.0 & 4.8 & 7.8 & 8.8 & 3.8 & 4.0 \\
\hline $\mathrm{G}$ & 120 & 11 & 19 & 47 & 57 & 5.8 & 6.0 & 6.4 & 8.1 & 6.7 & 5.9 \\
\hline $\mathbf{H}$ & 70 & 9 & 14 & 23 & 38 & 5.4 & 5.9 & 6.9 & 7.6 & 11.1 & 21.4 \\
\hline I & 120 & 12 & 30 & 52 & 86 & 4.5 & 5.5 & 6.0 & 7.2 & 18.0 & 28.3 \\
\hline $\mathrm{J}$ & 110 & 9 & 16 & 44 & 54 & 4.8 & 5.5 & 6.8 & 7.7 & 10.0 & 11.1 \\
\hline $\mathrm{K}$ & 80 & 8 & 12 & 30 & 38 & 5.4 & 6.7 & 7.6 & 9.0 & 3.1 & 5.7 \\
\hline $\mathbf{L}$ & 70 & 11 & 16 & 38 & 43 & 4.6 & 6.3 & 5.9 & 7.8 & 2.9 & 2.6 \\
\hline
\end{tabular}

$\dot{\mathrm{V}}_{\mathrm{E}}$, Ventilation rate; $\mathrm{P}_{\mathrm{ET}} \mathrm{CO}_{2}$, End tidal carbon dioxide concentration; Slope, Slope of $\dot{\mathrm{V}}_{\mathrm{E}}-\mathrm{P}_{\mathrm{ET}} \mathrm{CO}_{2}$ relationship; Rest, At rest; Exercise, During exercise; Air, Breathing air; $\mathrm{CO}_{2}$, Breathing $3 \%$ carbon dioxide.

Table 2 shows exercise intensities, ventilation rates, end-tidal $\mathrm{CO}_{2}$ concentrations and slopes for a $\mathrm{CO}_{2}$ response line. The values during rest and exercise were 1 -min averages taken from 1 to $2 \mathrm{~min}$ for the rest condition and after becoming stable for the exercise condition. And the slopes for the $\mathrm{CO}_{2}$ response line were defined by the equation,

$$
\mathrm{S}=\left[\dot{\mathrm{V}}_{\mathrm{E}}\left(\mathrm{CO}_{2}\right)-\dot{\mathrm{V}}_{\mathrm{E}}(\text { air })\right] /\left[\mathrm{P}_{\mathrm{ET}} \mathrm{CO}_{2}\left(\mathrm{CO}_{2}\right)-\mathrm{P}_{\mathrm{ET}} \mathrm{CO}_{2} \text { (air) }\right]
$$

where $S$ is the slope for the $\mathrm{CO}_{2}$ response line, $\dot{V}_{E}$ is the ventilation rate, and $\mathrm{P}_{E T} \mathrm{CO}_{2}$ is the end-tidal $\mathrm{CO}_{2}$ concentration. Air and $\mathrm{CO}_{2}$ in parentheses show the test conditions that the subject breathed air and $3 \% \mathrm{CO}_{2}$, respectively.
Figure 4 shows the relationship between the slope (S) at rest and during exercise for each subject. There was a close correlation between the slopes in the two conditions $(\mathrm{CC}=0.97)$ with the slopes during exercise about 1.7 times those at rest. Another notable characteristic of the ventilatory response was the large difference between test subjects in the values. During exercise, the slope of the most sensitive person to $\mathrm{CO}_{2}$ was more than 10 times as high as that of the least sensitive person.

\section{Discussion}

The increase in ventilation rate causes severe stress in the human body, especially if the person is using a respiratory protective device with breathing resistance, 


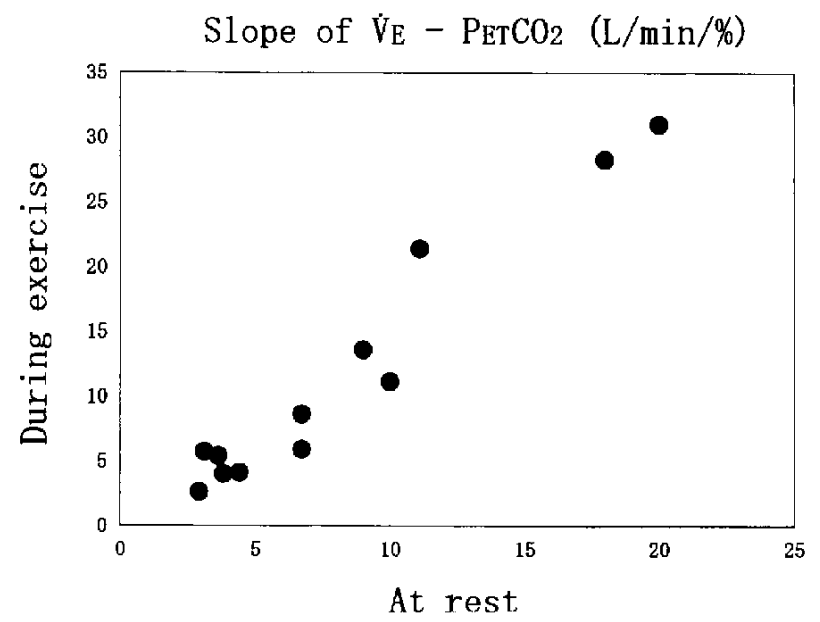

Fig. 4. Individual values in $\dot{\mathrm{V}}_{\mathrm{F}}-\mathrm{P}_{\mathrm{tT}} \mathrm{CO}_{2}$ relationship slope at rest and during exercise

since it produces higher pressure fluctuations requiring greater energy expenditure ${ }^{8-12)}$. One of our concerns about the safety of using respiratory protective devices was the effect of $\mathrm{CO}_{2}$ on the human body under work conditions. In order to determine the appropriate performance criteria for testing CCBA, the permissible inhaled $\mathrm{CO}_{2}$ concentration should be evaluated considering $\mathrm{CO}_{2}$ sensitivity during exercise. The slope of the $\dot{\mathrm{V}}_{\mathrm{E}}-\mathrm{P}_{\mathrm{HT}} \mathrm{CO}_{2}^{2}$ relationship is considered to be an important practical factor indicating the human sensitivity to $\mathrm{CO}_{2}$.

Read's rebreathing technique ") has been commonly used for measurement of ventilatory response to $\mathrm{CO}_{2}$. The advantages of this method are its simplicity and speed. Read's method requires the subject to breathe from a $4-6 \mathrm{~L}$ bag which initially contains $7 \% \mathrm{CO}_{2}$ and $50 \%$ oxygen. But the method has been suggested to be susceptible to error during exercise, since the method is based on the assumption that there is equilibrium between the partial pressure of $\mathrm{CO}_{2}$ between the rebreathing bag, alveolar, arterial blood and the tissues of the central chemoreceptors $^{21}$. However, the higher oxygen consumption rate during exercise can lead to a rapid decrease in bag volume which can change the equilibrium in $\mathrm{PCO}_{2}$ between the bag and the chemoreceptors ${ }^{2,13}$. And the high inspired $\mathrm{CO}_{2}$ concentration with this method can cause an artificial change in the slope because it leads fairly quickly to a maximum ventilation rate and produces a flattening off in the $\mathrm{CO}_{2}$ response curve ${ }^{2,13)}$. Duffin ${ }^{2)}$ demonstrated that during $50 \mathrm{~W}$ exercise the maximum limits of ventilation were reached too quickly to yield an accurate response slope. So most of the research studies with the rebreathing method were limited to light exercise. Those studies found that the ventilatory response to $\mathrm{CO}_{2}$ during exercise was unchanged from that at rest ${ }^{2-6}$.

This study, using the steady-state method, found that the ventilatory responses to $\mathrm{CO}_{2}$ during exercise were higher than those during rest. McConnell ${ }^{13)}$ and Clark ${ }^{14)}$ also used the steady-state method to measure $\mathrm{CO}_{2}$ response during exercise, and have reported an increase in responsiveness compared to rest conditions. Most of the work rates in these studies were moderate. But McConnell also compared the results of the steady-state method in rest and light exercise, and found the same tendency as in moderate exercise. So it is difficult to attribute the discrepancy between the results for the two methods to the difference in given work loads. Although, at the present time, we cannot determine the reason for the discrepancies, we believe that the steady-state method is the correct one to use in order to evaluate the appropriateness of the permissible inhaled $\mathrm{CO}_{2}$ level for CCBA. And the reasons are based on the fact that the work rate in the present study was moderate and that the inhaled $\mathrm{CO}_{2}$ concentration of the test was $3 \%$. Moderate work loads are assumed to be common in practical use of the apparatus ${ }^{15}{ }^{16}$, and $3 \% \mathrm{CO}_{2}$ is the same as the present permissible limit for inhaled $\mathrm{CO}_{2}$ in $\mathrm{JIS}^{7}$.

Under work conditions the effect of increased inhaled $\mathrm{CO}_{2}$ on ventilation is stronger than that at rest. The slopes of the $\dot{\mathrm{V}}_{\mathrm{E}}-\mathrm{P}_{\mathrm{ET}} \mathrm{CO}_{2}$ relationship have been demonstrated to be about $70 \%$ greater in moderate exercise than at rest. So, for reasons of safety in the use of CCBA, which tends to be used under work conditions, the permissible limit for inhaled $\mathrm{CO}_{2}$ of $3 \%$ is not appropriate. A minimal concentration is certainly desirable, but technical difficulties may prevent the achievement of a $\mathrm{CO}_{2}$ level as low as $1 \%$. We therefore recommend an inhaled $\mathrm{CO}_{2}$ limit of $2 \%$ which we believe is achievable with present technology.

We must also consider the wide range of individual sensitivity. Among the 12 test subjects in this study, the ventilatory response of the most sensitive subject was more than ten times that of the least sensitive. This wide range in individual $\mathrm{CO}_{2}$ response has been demonstrated in previous studies conducted at rest. McGurk ${ }^{171}$ reviewed the previous studies of ventilatory response to $\mathrm{CO}_{2}$ and found that the highest $\mathrm{CO}_{2}$ sensitivity was about 20 times as high as the lowest. We can assume the same range in sensitivity under work conditions, because the present study showed a close correlation between sensitivity at rest and at work. For safety reasons, in rescue or fire fighting activities, a person with a high ventilatory response to $\mathrm{CO}$, must be excluded from CCBA use. Increase in inhaled $\mathrm{CO}_{2}$ in an apparatus can increase the ventilation rate of a highly sensitive person to the extent that the severe stress might cause a dangerous situation. The rebreathing method can be used to identify those persons because of the close correlation between the ventilatory response to $\mathrm{CO}_{2}$ at rest and during exercise. This is fortunate because the conventional rebreathing method is more easily performed. 
Acknowledgment: We are very grateful to Dr. Nicholas Kyriazi of the U.S. National Institute for Occupational Safety and Health for constructive comments during the preparation of this manuscript.

\section{References}

1) Read DJC, A clinical method for assessing the ventilatory response to carbon dioxide. Australas Ann Med 1967: 16: 20-32.

2) Duffin J, Bechbache RR, Goode RC, Chung SA. The ventilatory response to carbon dioxide in hyperoxic exercise. Respiration Physiol 1980; 40: 93-105.

3) Mucci P, Prioux J, Hayot M, Ramonatxo M, Prefaut C. Ventilation response to $\mathrm{CO}_{2}$ and exercise-induced hypoxaemia. Eur J Appl Physiol 1998; 77: 343-351.

4) Mercier J, Ramonatxo M, Prefaut C. Hyperpnoea and $\mathrm{CO}_{2}$ sensitivity of the respiratory centres duirng exercise. Eur J Appl Physiol 1990; 59: 411-415.

5) Duffin J, Mcavoy GV. The peripheral-chemoreceptor threshold to carbon dioxide in man. J Physiol 1988; 406: 15-26.

6) Martin BJ, Well JV, Sparks KE, Mccullough RE, Grover RF. Exercise ventilation correlates positively with ventilatory chemoresponsiveness. J Appl Physiol 1978; 45: 557-564.

7) Japanese Standards Association, Closed-circuit oxygen self-rescuers. JIS M 7651, 1996 (in Japanese).

8) Takahashi M, Mano Y, Shibayama M, Yamami N. Effects of breathing resistance while inlaling $3 \%$ carbon dioxide during steady-state exercise. J Occup Health 1998; 40: 213-217.

9) Cerretelli P, Sikand SR, Farhi LE. Effect of increased airway resistance on ventilation and gas exchange during exercise. J Appl Physiol 1969; 27: 547-600.

10) Craig FN, Blevins WV, Cummings EG. Exhausting work limited by external resistance and inhalation of carbon dioxide. J Appl Physiol 1970; 29: 847-851.

11) Hermansen L, Vokac Z, Lereim P. Respiratory and circulatory response to added air flow resistance during exercise. Ergonomics 1972; 15: 15-24.

12) Demedts $M$, Anthonisen NR. Effects of increased airway resistance during steady-state exercise. J Appl Physiol 1973; 35: 361-366.

13) McConnell AK, Semple ESG. Ventilatory sensitivity to carbon dioxide: the influence of exercise and athleticism. Med Sic Sports Exerc 1996; 28: 685-691.

14) Clark JM, Sinclair RD, Lenox JB. Chemical and nonchemical components of ventilation during hypercapnic exercise in man. J Appl Physiol 1980; 48: 1065-1076.

15) Kamon E, Doyle D, Kovac J. The oxygen cost of an escape from underground coal mine. Am Ind Hyg Assoc J 1983; 44: 552-555.

16) Lemon PWR, Hermiston RT. The human energy cost of fire fighting. J Occup Med 1977; 19: 558-562.

17) McGurk SP, Blanksby BA, Anderson MJ. The relationship of hypercapnic ventilatory responses to age, gender and athleticism. Sports Med 1995; 19: 173-183. 